\title{
PROBLEMS AND PROSPECTS OF FISH FRY TRADE IN JESSORE DISTRICT OF BANGLADESH
}

\author{
M. M. Rahaman, M. A. Sayeed ${ }^{1}$, A. Paul and M. Nahiduzzaman ${ }^{1}$ \\ Department of Fisheries, People's Republic of Bangladesh, Dhaka, Bangladesh
}

\begin{abstract}
A study was conducted to investigate the existing system of fry trade and different problems and prospects associated with this enterprise in Jessore district. A total of 82 hatchery operators and nursery owners were interviewed using a structured questionnaire. In the study period $4211.5 \mathrm{~kg}$ hatchling were produced in 85 hatcheries in this area of which $80 \%$ were reared in the same area. Average price of per $\mathrm{kg}$ hatchling were Indian major carps- Tk.1200 to 1800, Chinese carp Tk. 1200 to 1600 and Thai sharpunti and pungus- Tk. 900 to 1200. A total 1621 lacs of 1-4" sized fry was produced during the study period. Among them Indian major carp 864.3 lacs (53.32\%), Chinese carp 621.9 lacs $(38.36 \%)$, Thai sharpunti and pangus 134.8 lacs $(8.32 \%)$. The fry mortality was observed $24 \%( \pm 1.92)$ due to improper management. The aratdar and middlemen were controlling the marketing system. As a consequence, fry traders and nursery operators have been facing several problems in this business. The main constrains were lack of capital (35\%) followed by lack of technical knows-how $(27 \%)$ faced by fry traders. The nursery operators faced the problems like lack of capital (31\%), high lease value $(25 \%)$, high price of production inputs $(17 \%)$, terrorism $(12 \%)$, intense market competition $(9 \%)$ and the lack of policy support $(6 \%)$. As Jessore contributes fifty percent of total fry and fingerling production in Bangladesh, therefore, the stakeholders should focus on the trade issues, otherwise fish supply would be interrupted as a whole.
\end{abstract}

Key Words : Fish fry trader, Hatchery and nursery operator, Business constraints, Middlemen

\section{INTRODUCTION}

In past, the rivers of Bangladesh were the major natural source of carp seed production. Millions of eggs and spawn were collected from the rivers during monsoon (MayAugust). In 1984 the spawn production in Bangladesh was 93.86\% (23657 kg), 3.55\% (895 $\mathrm{kg}$ ) and 2.59\% (625 kg), respectively from Padma-Brahmaputra river system, from Halda river and from all hatcheries respectively (Tasi and Ali, 1997). Due to the destruction of natural habitats and also increased demand, the natural availability of carp seed has largely declined and the aquaculture venture are gradually replaced by the hatcheryproduced fry since early $80^{\prime}$ s when artificial fish breeding techniques and low cost hatchery designs have been successfully adapted in Bangladesh (Islam, 1989).

\footnotetext{
${ }^{1}$ Department of Fisheries Biology and Genetics, Bangladesh Agricultural University, Mymensingh
} 
In recent years, there has been a phenomenal growth in the number of hatcheries, especially in the private sector. In 1982 there were only 3 private hatcheries in Bangladesh. The number has increased to 40 by 1985 and to 214 by 1987 (Islam, 1989) and reached to 756 in 2004. Their production of 4 to 5 days old larvae (i.e. spawn) was increased from 4,962 $\mathrm{Kg}$ in 1985 to 3,50,029 $\mathrm{kg}$ in 2004 with a an increment rate 170 percent annually, while the quantity of spawn collected from natural sources was reduced from 19,362 kg in the year of 1980 to $1577 \mathrm{~kg}$ in 2004 (DoF, 2004)).

The production of carp seeds through induced breeding has made a real progress in aquaculture of the country. The hatchery produced hatchling cannot be directly stocked in the culture ponds as they need to rear an intermediate stage in a nursery pond before stocking in the culture pond. A number of fish fry nurseries have been grown alongside the hatcheries. The output from nurseries is the actual fish seed production from the country. In Bangladesh, there are about 918 private nurseries, with an average area of 1 ha each and 82 Government nurseries covering an area of about 60 ha. In 1987, private nurseries produced about 666 million fingerlings of 2-3" size. While the public sector farms produced about 30 million fingerlings (Islam, 1989).

Fish hatcheries and nurseries were not grown in symmetry in all region of Bangladesh. Jesorre district is the centre point for fry and hatchling production as it is a potential and profitable business avenue in this region. Approximately $45,000 \mathrm{~kg}(21 \%$ of the total hatchling production of the country) is produced per year in Jessore (DoF, Jessore, 2002). Hence, the survivability of the hatchlings, socio-economic impact on fish farmers and the economic analysis of the hatchery operation has not been quantified. On the basis of assumption and observation a positive impact of hatchery produced spawn has been seen on the enhancement of fish production (Nuruzzaman, 1989). The present communication aimed to study the existing system of fry trade and also find out different problems and prospects in this enterprise. As the study showed an overview of present status and future prospect of fish nursery trade in Jessore region, it would add a new knowledge in the field of fish fry trade and build a foundation for further research, planning and developing programme for improving efficiency of this business enterprise.

\section{MATERIALS AND METHODS}

The study was conducted on 82 nursery operators and customers of Sadar, Monirampur and Bagherpara upazila of Jessore district. Both the nursery operators and the customers were selected randomly. A structured questionnaire was prepared emphasizing on pond ownership, nursery layer, and number of employees, sources of spawn, fingerling production, survival rate, market system, sources of capital and constrains in the trade etc. for collecting information to pertinent the study objectives. Pre-test was done before finalization of the questionnaire. Data collection was made during pick season (June to October, 2002) of the business. Data were analyses using simple arithmetical calculation such as mean, percentage with computer based MS Excel program. 
There are some limitations of the study that the nursery owners hardly kept systematic record of year wise purchase and sell data. They supplied data from their memory and thus in most cases it was difficult to get accurate information.

\section{RESULTS AND DISCUSSION}

\section{Pond and fry rearing status}

Most of the nursery operators in survey area performed their business in three to nineteen ponds with an average area of $2.45( \pm 1.36)$ ha (mean \pm SD). In the present study it was found that about $47 \%$ of the total nursery operators used their own ponds in their business. Carp seed production through induced breeding in Jessore region has made a real progress in inland freshwater aquaculture. The lease value for each hector per year in Chanchra was doubled (Tk. 90-110 thousands) than those were in Manirampur and Bagharpara (Tk. 45-55 thousands). Due to high lease value the nursery operators conduct more cycles in a year with a view to compensate excessive lease cost. Among the nursery operators, $34.1 \%$ were used to complete $6-8$ cycles/year and $29.2 \%$ used to complete $8-10$ cycles/year. Cent percent of the nursery operators of this area followed two layer nursery systems. In this system $31.7 \%$ nursery operator completed their cycles within $25-$ 30 days, $28.05 \%$ within $30-35$ days, $25.6 \%$ within $20-25$ days and $8.53 \%$ within $35-40$ days respectively to get fingerlings up to 3-4 inch size. According to Islam (1989), in two stages nursing, fry are reared for a period of 4-6 weeks at a density of 1 million/ha, by which time they rich a size of 2-3 inch. Hatchlings, collected from natural sources or produced by induced breeding, reared for one to two months in earthen rearing ponds to a size of about 2.5-3.5 inch before being sold to the pond culturists (Hasan, 1990).

\section{Manpower}

About $4.8( \pm 3.92)$ persons were engaged in each nursery but the permanent manpower was minimal. During the production season a large number of labors get involved as full time basis. Apart from those full-time labours, the nursery operators had to hire the part time labour in every week for harvesting, pond repair and other related works. In each nursery there were $3.2( \pm 2.43)$ and $5.7( \pm 3.15)$ full-time labours and per time labours involved in peak season. Hence, this enterprise creates employment opportunities for the local people.

\section{Source of spawn and hatchling production}

There were 85 hatcheries operated in the Jessore district of which $97.65 \%$ and $2.35 \%$ situated in sadar and Monirampur upazilla, respectively. The fry traders of the district collect spawn from the hatchery situated in Chanchra region except two owner of Monirampur upazilla who uses all of their spawns from their own nurseries. It was found that total $42,111.5 \mathrm{Kg}$ hatchlings were produced from these hatcheries in the year 2002. About $80 \%$ of the hatchlings were reared in the study area and the rest were reared in other areas of the country. 


\section{Price of hatchling}

The entire nursery operators purchased hatchling from the hatchery situated in Chanchra region. Some nursery operators purchased hatchling from local hatchery situated in his upazilla and stock it in the nursery pond. The price of the hatchling of different species is different. This was due to the inconsistent demands of the species to the customers, availability, season and growth rate of the species and culture system. Average per $\mathrm{kg}$ price of hatchling are Cyprinus carpio var flavipinnis and Cyprinus carpio var specularisTk.1000 to 1600, Labio rohita, Catla catla and Cirrhinus cirrhosus - Tk. 1200 to 1800, Puntius gonionotus- Tk. 900 to 1200, Hypopthalmichthys molitrix and Ctenopharyngodon idella Tk. 1200 to 1500.

\section{Survival}

The survival rate of the spawn was $60-70 \%$ claimed by $19.5 \%$ nursery operator, $70-80 \%$ claimed by $47.5 \%$ nursery operator, $80-90 \%$ claimed by $28 \%$ nursery operator and $90-100$ claimed by $5 \%$ nursery operator. From the above result, it was found that about half of the total nursery operator claimed the survival was $70-80 \%$ with a average value of $76 \%$ ( \pm 1.92 ). This was due to lack of proper pond management, optimum level of water quality parameters and lack of technical knowledge. Transportation hazards also cause mortality to some extent. Islam (1989) showed in a study the survival rate of the transported spawn was $70 \%$.

\section{Production of fry}

From the study, it was observed that total 1621 lacs fry of 1-4" size was produced in the district during the year 2002. Among them silver carp possesses the highest position in fry production 386.7 lacs (25\%) followed by Rohu 345 lacs (21\%), Catla 321.9 lacs (20\%), Mrigal 197.4 (12\%), Common carp 183.5 (11\%), Thai Puti 104.3 lacs (6\%), Grass Carp 51.7lacs $(3 \%)$ and pangus 30.5lacs $(2 \%)$ which is shown in Fig. 1.



Fig. 1. Contribution to fry Production of different species in some selected nurseries 


\section{Fry mareting channel}

Fry produced from the nurseries in the area distributed among the upazillas of Jessore district as well as in most part of the country. Jessore is one of the most important fry markets of the country. More than $50 \%$ fry demand of the country is met by Jessore district. Fry traders used to come from Bogra, Natore, Pabna, Kushtia, Dhaka, Manikgonj, Comilla, Chandpur, Barisal, Faridpur, Khulna, Satkhira and other district of the country. Marketing channel are the alternative routes of product flows from producer to consumer (Khols and Uhi, 1980). In the study, it was found that the marketing channel (Fig. 2) consists of hatchery owner; Nursery owner, aratdar, fry seller and pond owner.

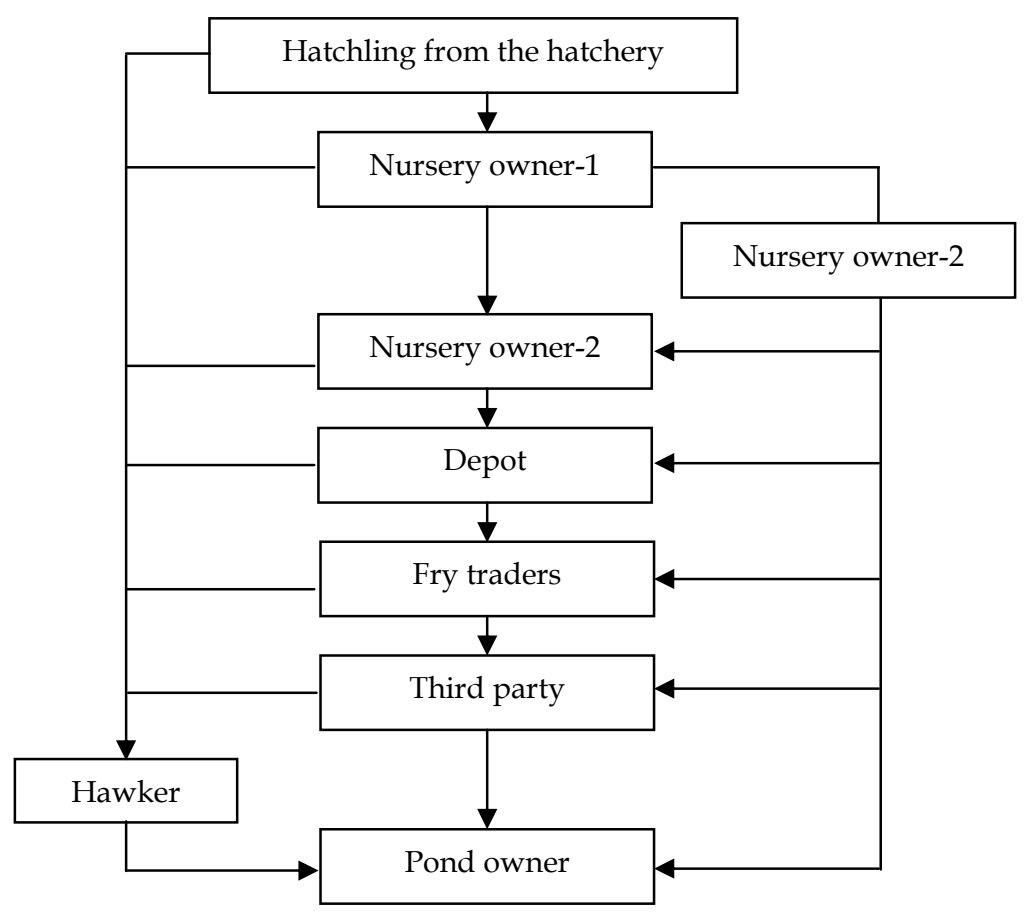

Fig. 2. Fry marketing channel

The marketing of fingerlings was generally done by the middlemen, since a very few fish farmers buy the seed directly from the nursery farms. Aratdar was the main customer of the nursery operator and it was reported by $45.2 \%$ farmers. Aratdar sold the fry to the middlemen or the retailers and they used to sell to the pond owners. The middlemen bought the fingerlings from the nursery operators on cash payment and sold them to pond owners at a profit of $100-200 \%$ on credit (Islam, 1989). It was found that the problems associated with fry marketing were created by the invasion of intermediaries and the nursery owner did not get the actual price of fry which was paid by the pond owner. 


\section{Transportation}

The fry were transported by bus, pick- up van, truck, and train. In local markets the fry were transported by manual van, public bus and in some cases by truck. But train or pick-up vans were found to be the main transport to the distant district (Table 1).

Table 1. Modes of transportation used by fry traders and buyers

\begin{tabular}{lccccc}
\hline \multicolumn{1}{c}{ Type of transport } & No. of farmer & Percentage (\%) & No. of buyer & Percentage (\%) \\
\hline Pick-up van & 44 & 53.6 & 8 & 36.4 \\
Bus & 13 & 15 & 10 & 45.5 \\
Manual van & 25 & 30.4 & - & - \\
Train & - & - & 4 & 18.1 \\
\hline Total & 82 & 100 & 22 & 100 \\
\hline
\end{tabular}

Transportation of live fish is wide spread practice particularly in the rural areas of developing countries and often represents the only means of supplying fry/fingerlings for culture (Ross and Taylor, 1989). The fry traders usually followed the traditional approach of fry carrying. They normally used aluminum pot or plastic barrel with no specified densities. For oxygen supply they always agitated the water in the pot or plastic barrel continuously during transportation. For long period of transportation they also change water of the pot or plastic barrel. In Bangladesh, spawn, fry and fingerlings are transported traditionally in earthen/aluminum hundies (pots). Density of fish seed transported through this method is not based on any scientific basis, but on pragmatic knowledge resulting in high mortality. Traders are aware of the fish seeds' requirement for oxygen and thus they continuously agitate the water in the hundies during transportation (Haq et al., 1991).

Transportation system as a whole was disappointing here. The prevailing fry transportation system is traditional as described by Saha and Chowdhury (1956), and results in lowering of vitality of the fry and resultant mortality. It was reported in the study area that 20 to $30 \%$ mortality of fry were caused due to transportation claimed by $44 \%$ customers. Modern technique of fish seed transportation is by using polythene bag filled with oxygen and fish hauling tank with agitator (Haq et al., 1968). The densities of fingerlings computed for transportation in eight liters of water under oxygen packing at $30^{\circ} \mathrm{C}$ temperature are 150, 80 and 4 fingerlings for 6, 12 and 24 hours duration of transport, respectively (Santhanam et al., 1999).

\section{Constraints of fry and fingerling trading}

Fry and fingerling traders have been faced several barriers to operate their business. Lack of capital (35\%) was the vital problem in developing the business followed by the lack of technical knows how (27\%) as stated by the survey respondents (Table 2). However, the main sources of capital of fry traders were from their inherited and own sources (37\%), local money lender $(32 \%)$, bank loan $(18 \%)$, and other family sources $(13 \%)$. The paid interest rate of scheduled bank and local money lenders was $12 \%$ and $36 \%$ respectively. . 
The poor and marginal farmers have little access to the institutional credits operated by few commercial banks in Bangladesh. Although a few of the rural banks viz., The Grameen Bank operates provide credits to the rural farmers with a high success of utilization (Shah, 1991). But traditional micro credit system does not fulfill what the amount they need and on the other hand weekly installment might hamper money flowing into their business. In addition multi-ownership is another problem for getting credit in this sector. It is also reported that Bank officials are not familiar with fisheries activities and not trained in identifying the credit request.

Table 2. Ranking the constraints of fry and fingerling trading

\begin{tabular}{c|c|c}
\hline Rank & Constraints & Percentage (\%) \\
\hline 1 & Lack of capital and credit facilities & 35 \\
3 & Lack of technical know how & 27 \\
3 & Lack of using modern equipment and facilities & 18 \\
4 & Intense market competition & 12 \\
5 & Market fluctuation & 8 \\
\hline
\end{tabular}

Nursery operations have been carried out on the basis of practical experience that they have achieved since a long working tenure. They often fail to interpret the field situation as a result they might face economic losses due to such diagnosis failure. It was found that only $25 \%$ of the nursery operators received training from Department of Fisheries (DoF) and Department of Youth Development (DYD) and the rest had no technical knowledge. The third, fourth and fifth ranked constraints were the lack of using modern equipment and facilities (18\%), intense market competition (12\%) and market competition $(8 \%)$ (Table 2$)$.

\section{Problems faced by the nursery owners}

The nursery farmers were found to face various problems which are more or less common as like as other parts of the country. As given in Table 3, the ranked problems are the lack of capital (31\%), high lease value $(25 \%)$, high price of production inputs $(17 \%)$, terrorism $(12 \%)$, intense market competition $(9 \%)$ and the lack of policy support $(6 \%)$. The lease value of nursery pond varies considerably from place to place. The lease value of Chanchra region in Jessore district was Tk. 90,000 to 110,000 ha-1 year-1 and it was Tk. 45000 to 55,000 ha-1 year-1 both at Manirampur and Bagharpara.

Table 3. Ranking of the problems faced by the nursery operators

\begin{tabular}{c|c|c}
\hline Rank & Constraints & Percentage (\%) \\
\hline 1 & Lack of capital and credit facilities & 31 \\
3 & High lease value of pond & 25 \\
3 & High price of production inputs & 17 \\
4 & Terrorism & 12 \\
5 & Intense market competition & 9 \\
6 & Lack of policy support & 6 \\
\hline
\end{tabular}


In addition that, most of the nursery owner mentioned that they had to purchase seed, fertilizer, feed and other inputs with a very high price during pick season. Market fluctuation often causes a big loss in their business. The lack of required policies created the opportunity not comply the rules and regulation and have been maintained only compliance what they set for themselves.

\section{CONCLUSION}

The success of the pond aquaculture over the country depends mostly on the availability of quality spawn/fry. However, carp seed production is still very poor in Bangladesh so that it cannot fulfill/satisfy the demand. In the field of nursery operation in Bangladesh no mordern technologies have so far been practiced by the nursery operators as like hatchery technology. Nursery operation is the consecutive step of hatchery operation as well as pond fish culture. Therefore it is nearly of every bodies interest that nursery trade in Jessore region playing a vital role in producing the carp spawn / fry not for only in Jessore region but also for the whole country. In spite of high potentiality, there are some barriers in this trade which is hindering the growth of sector. Bangladesh government as well as the other stakeholders in this sector should play vital role to save this prospectus sector. This will eventually help in poverty reduction through creating employment opportunity and overall socio-economic condition will be uplifted and national production target will be achieved.

\section{REFERENCES}

DoF, 2002.Annual Hatchery and Nursery Report, 2002. Department of Fisheries, Ministry of Fisheries and Livestock, Government of the Peoples Republic of Bangladesh, pp. 10-14.

DoF, 2002. Fish Fortnight Compendium, Department of Fisheries, Ministry of Fisheries and Livestock, Government of the Peoples Republic of Bangladesh, pp. 50-54.

DoF, 2004. Fish Fortnight Compendium, Department of Fisheries, Ministry of Fisheries and Livestock, Government of the Peoples Republic of Bangladesh, pp. 71-74.

Haque, M. J. 1992 Control of predatory and undesirable species. Nursery Pond Management, Trainers Training Manual FRI, Mymensingh. pp. 4-19.

Haque, M. Z., Rahman, M. A. and Shah, M. S. 1991. Studies on the density of Rohu (Labeo rohita) fingerlings in polyethylene bags, for transportation. Bangladesh J. Fish., 14(1-2) : 145-148.

Hasan, M. R. 1990. Aquaculture in Bangladesh, Aquaculture in Asia (Chap-4). MM Joseph ed. Asian Fisheries Society, pp. 106-140.

Huq, M. F., Tilton, J. K. and Haque, A. K. M. A. 1968. On the use of oxygen for the transportation of carp fry and fingerlings in East Pakistan. Pak. J. Biol. and Agric. Sci., (1) : 37-42.

Islam, M. A. 1989. Fish Seed production in Bangladesh. Proceeding of the SAARC Workshop on Fish seed Production, 11-12 June, Dhaka, Bangladesh. pp. 1-12.

Islam, Z. and Chowdhury, A. Q. 1976. Induced spawning of Major Carps for Commercial production of fry in the Fish Seed Farm. Bangladesh J. Zool. 4(2) : 51-61.

Kohls, R. L. and Uhi, J. N. 1980. Marketing of Agricultural Products (5 $5^{\text {th }}$ ed.), Macmillon publishing Co. Inc., New York. 
Nuruzzaman, A. K. M. 1989. Socio-economic Consideration of Fish Seed Production in Bangladesh. Proceeding of the SAARC Workshop on Fish seed Production, 11-12 June, Dhaka, Bangladesh. pp. 60-71.

Ross, L. and Tailor, N. I. 1989. Fry transportation (Small scale system using hydrogen peroxide). Aquaculture News No., $8: 15$.

Saha, K. C. and Chowdhury, N. K. 1956. Studies on the mortality in spawn and fry of Indian major carps during transport. Indian J. Fish. (1): 119-26. Cited in FAO Fish. Synops. (32).

Santhanam, R., Sukumaran, N. and Natarajan, P. 1999. A Manual of Fresh Water Aquaculture. New Delhi. pp. 83.

Shah, M. S. 1991. Strategies for Aquaculture Development in Bangladesh. Tilzer, M. M. \& M. Khondker (eds), Hypertrophic and Polluted Freshwater Ecosystems: Ecological Bases for Water Resource Management. Proc. Int. Symp. Limnol, 25-28 November 1991. Department of Botany, University of Dhaka, Dhaka, Bangladesh, Publi. 1993. pp. 215-221.

Tasi, C. and Ali, M. Y. 1997. Open Water Fisheries of Bangladesh. Bangladesh Center for Advanced Studies. 